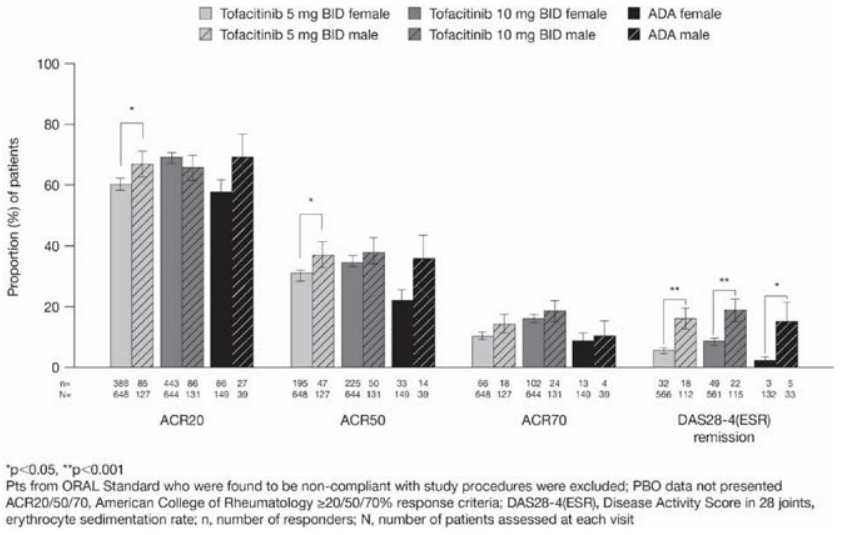

Conclusion: Efficacy outcomes with tofacitinib and ADA were generally higher in males and comparable in females vs previously reported mixed population response rates for advanced therapies. Safety findings did not reveal a consistent pattern between sexes. Tofacitinib persistence was similar between sexes. Acknowledgements: Study sponsored by Pfizer Inc. Medical writing support was provided by Christina Viegelmann, CMC Connect, and funded by Pfizer Inc. Disclosure of Interests: H Niall Jones Consultant of: Pfizer Inc, Vibeke Strand Consultant of: AbbVie, Amgen, Arena, AstraZeneca, Bayer, Boehringer Ingelheim, Bristol-Myers Squibb, Celltrion, Corrona, Eli Lilly, Galapagos, Genentech/ Roche, Gilead, GlaxoSmithKline, Ichnos, Inmedix, Janssen, Kiniksa, Merck, Myriad Genetics, Novartis, Pfizer Inc, Regeneron, Samsung, Sandoz, Sanofi, Scipher, SetPoint Medical, UCB, Hendrik Schulze-Koops Consultant of: AbbVie, Amgen, Biogen, Bristol-Myers Squibb, Celgene, Eli Lilly, Gilead Sciences, Hexal Sandoz, Hospira, Janssen-Cilag, MSD, Novartis, Pfizer Inc, Roche, UCB, Grant/ research support from: Novartis, Pfizer Inc, Eduardo Mysler Speakers bureau: AbbVie, Bristol-Myers Squibb, Eli Lilly, Janssen, Pfizer Inc, Roche, Sanofi, Grant/ research support from: Eli Lilly, Pfizer Inc, Roche, Cassandra Kinch Shareholder of: Pfizer Canada ULC, Employee of: Pfizer Canada ULC, David C Gruben Shareholder of: Pfizer Inc, Employee of: Pfizer Inc, Rebecca Germino Shareholder of: Pfizer Inc, Employee of: Pfizer Inc, Carol A. Connell Shareholder of: Pfizer Inc, Employee of: Pfizer Inc, Lihi Eder Speakers bureau: AbbVie, UCB, Consultant of: AbbVie, Celgene, Eli Lilly, Novartis, Pfizer Inc, UCB, Grant/research support from: AbbVie, Eli Lilly, Pfizer Inc, UCB DOI: 10.1136/annrheumdis-2021-eular.359

\section{POS0653 IMPACT OF UPADACITINIB OR ADALIMUMAB AS INITIAL THERAPY ON THE ACHIEVEMENT OF 48-WEEK TREATMENT GOALS IN PATIENTS WITH RHEUMATOID ARTHRITIS AND INADEQUATE RESPONSE TO METHOTREXATE: POST HOC ANALYSIS OF A PHASE 3 STUDY}

E. Mysler ${ }^{1}$, Y. Tanaka ${ }^{2}$, A. Kavanaugh ${ }^{3}$, D. Aletaha ${ }^{4}$, P. C. Taylor ${ }^{5}$, I. H. Song ${ }^{6}$, T. Shaw ${ }^{6}$, Y. Song ${ }^{6}$, R. Demasi ${ }^{6}$, M. Ali ${ }^{6}$, R. Fleischmann ${ }^{7}{ }^{1}$ Organización Medica de Investigación, Rheumatology, Buenos Aires, Argentina; ${ }^{2}$ The First Department of Internal Medicine, University of Occupational and Environmental Health, Kitakyushu, Japan; ${ }^{3}$ Division of Rheumatology, Allergy, \& Immunology, University of California San Diego Medical School, San Diego, United States of America; ${ }^{4}$ Division of Rheumatology, Department of Medicine 3, Medical University of Vienna, Vienna, Austria; ${ }^{5}$ Botnar Research Centre, Nuffield Department of Orthopaedics, Rheumatology and Musculoskeletal Sciences, University of Oxford, Oxford, United Kingdom; ${ }^{6}$ AbbVie Inc., Rheumatology, North Chicago, United States of America; ${ }^{7}$ Department of Medicine, University of Texas Southwestern Medical Center, Metroplex Clinical Research Center, Dallas, United States of America

Background: In the randomized, double-blinded, Phase 3 SELECT-COMPARE study, upadacitinib (UPA) + MTX demonstrated greater clinical and functional responses vs adalimumab (ADA) + MTX in patients (pts) with RA and inadequate response to MTX. ${ }^{1,2}$ Pts with insufficient response to initial therapy were switched from UPA to ADA (and vice versa) according to treat-to-target (T2T) principles. Objectives: We analyzed 1-year treatment outcomes in SELECT-COMPARE according to initial randomization group, regardless of whether pts subsequently switched therapy.

Methods: Pts initially randomized to UPA $15 \mathrm{mg}$ once daily (QD) or ADA $40 \mathrm{mg}$ every other week (EOW; both + MTX) for up to 48 weeks in SELECT-COMPARE were included in the analysis. As per the protocol-directed rescue strategy, pts experiencing $<20 \%$ improvement in tender or swollen joint counts at Week 14,18 , or 22, or Clinical Disease Activity Index (CDAI) $>10$ at Week 26, were switched from UPA to ADA or ADA to UPA in a blinded fashion. Efficacy outcomes included CDAl remission ( $\leq 2.8)$ and low disease activity (LDA; $\leq 10)$, DAS of 28 joints using CRP (DAS28[CRP]) $<2.6$ and $\leq 3.2$, and a composite of "deep response" (CDAl remission, HAQ-Disability Index $<0.5$, and pain score $<20$ ). Data are presented and attributed to initial randomized group (UPA or ADA) regardless of any subsequent switch in therapy. Time-averaged response rates were calculated as area under the curve of response rate standardized by 48 weeks. The proportions of pts who maintained Week 26 responses through 6 months of follow-up are also reported.

Results: This analysis included 651 pts initially randomized to UPA (of whom 245 switched to ADA) and 327 pts initially randomized to ADA (of whom 157 switched to UPA). Baseline characteristics including age, sex, and BMI were generally well balanced between randomized groups. At Week 48, similar proportions of pts initially randomized to UPA or ADA therapy achieved CDAI remission/ LDA $(27.6 \% / 61.9 \%$ vs $24.8 \% / 59.0 \%)$ and DAS28(CRP) $<2.6 / \leq 3.2(45.0 \% / 60.2 \%$ vs $43.7 \% / 59.0 \%$ ) (Figure 1). However, a small but significantly greater proportion of pts achieved a deep response with initial UPA vs initial ADA therapy $(17.8 \%$ vs $12.8 \% ; p<0.05)$. In addition, time-averaged response rates over 48 weeks were higher for initial UPA vs initial ADA therapy across efficacy outcomes. Similar trends were observed for other outcomes. Additionally, similar proportions of pts maintained Week 26 responses with initial UPA vs initial ADA therapy based on CDAI remission/LDA and DAS28(CRP) $<2.6 / \leq 3.2$ during 6-month follow-up (Table 1)

Conclusion: Using a stringent T2T approach to RA management, rates of LDA

Figure 1. Achievement of CDAI (A) and DAS28(CRP) (B) responses corresponding with time-averaged response rates over 48 weeks by initial therapy with UPA or ADA in SELECT-COMPARE

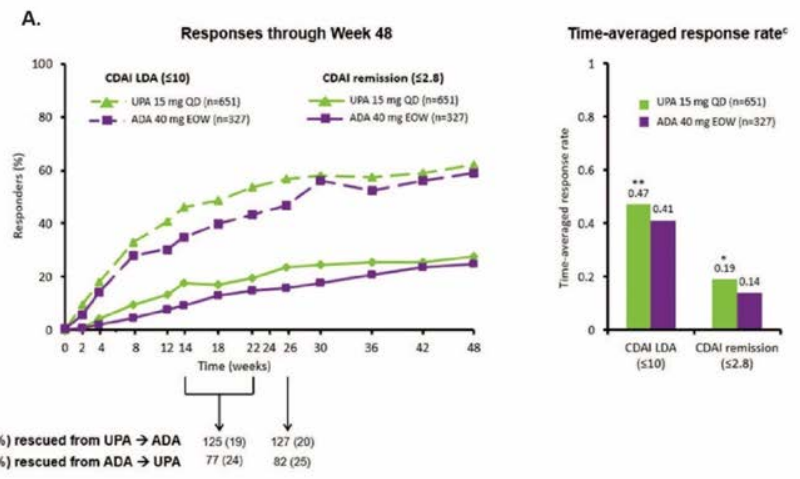

B.

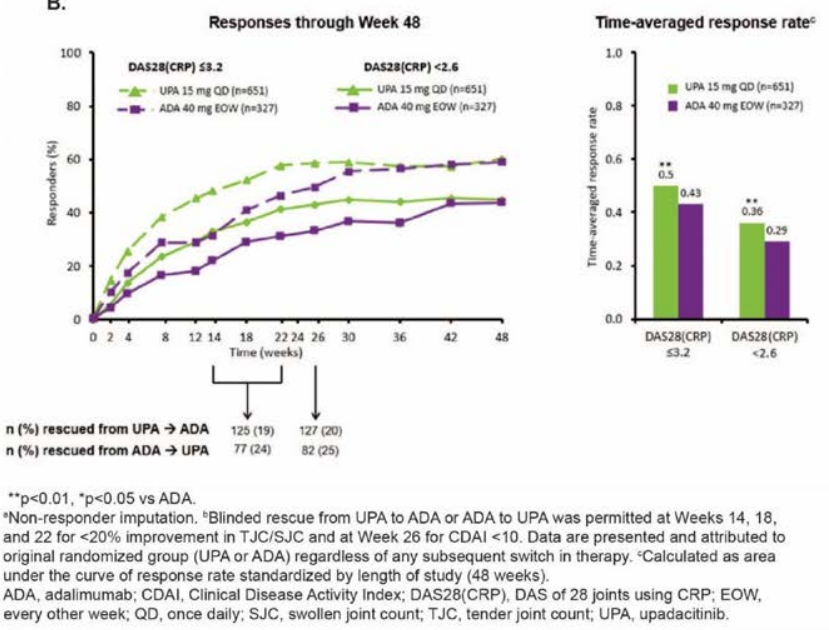

or remission at 1 year were similar, regardless of whether pts were initially randomized to UPA or ADA. However, initial UPA therapy led to more frequent deep responses and higher time-averaged response rates vs initial ADA therapy. REFERENCES:

[1] Fleischmann R, et al. Arthritis Rheumatol 2019;71:1788-800.

[2] Fleischmann R, et al. Ann Rheum Dis 2019;78:1454-62. 
Table 1. Proportion of patients maintaining Week $26 \mathrm{CDAl}$ and DAS28(CRP) responses during 6-month follow-up by initial therapy with UPA or ADA in SELECT-COMPARE ${ }^{\mathrm{a}-\mathrm{c}}$

\begin{tabular}{lcc}
\hline & UPA 15 mg QD & ADA 40 mg EOW \\
\hline CDAI LDA $(\leq 10)$ & 43.9 & 36.3 \\
CDAI Remission $(\leq 2.8)$ & 35.0 & 22.7 \\
DAS28(CRP) $\leq 3.2$ & 39.1 & 35.3 \\
DAS28(CRP) $<2.6$ & 30.5 & 30.1 \\
\hline
\end{tabular}

${ }^{\mathrm{a} A s}$ observed.

${ }^{\mathrm{b}}$ Blinded rescue from UPA to ADA or ADA to UPA was permitted at Week 14, 18, and 22 for patients with $<20 \%$ improvement in TJC or SJC and at Week 26 for patients with a CDAI $<10$. Data are presented and attributed to original randomized group (UPA or ADA) regardless of any subsequent switch in therapy.

cMaintaining response defined as never losing response at any visit during $~ 6$ months (22-26 weeks) follow up after first achieving response before or at Week 26.

ADA, adalimumab; CDAI, Clinical Disease Activity Index; DAS28(CRP), DAS of 28 joints using CRP; EOW, every other week; QD, once daily; SJC, swollen joint count; TJC, tender joint count; UPA, upadacitinib.

Acknowledgements: AbbVie funded this study and participated in the study design, research, analysis, data collection, interpretation of data, reviewing, and approval of the publication. All authors had access to relevant data and participated in the drafting, review, and approval of this publication. No honoraria or payments were made for authorship. Medical writing assistance was provided by Frances Smith, PhD, of 2 the Nth, which was funded by AbbVie.

Disclosure of Interests: Eduardo Mysler Consultant of: AbbVie, Amgen, Bristol-Myers Squibb, Eli Lilly, Janssen, Pfizer, Roche, and Sandoz., Grant/research support from: AbbVie, Amgen, Bristol-Myers Squibb, Eli Lilly, Janssen, Pfizer, Roche, and Sandoz., Yoshiya Tanaka Speakers bureau: AbbVie, Asahi Kasei, Astellas, Bristol-Myers Squibb, Eli Lilly, Chugai, Daiichi-Sankyo, Eisai, Gilead, GlaxoSmithKline, Janssen, Mitsubishi-Tanabe, Novartis, Pfizer, Sanofi, and YL Biologics, Consultant of: AbbVie, Asahi Kasei, Astellas, Bristol-Myers Squibb, Eli Lilly, Chugai, Daiichi-Sankyo, Eisai, Gilead, GlaxoSmithKline, Janssen, Mitsubishi-Tanabe, Novartis, Pfizer, Sanofi, and YL Biologics, Grant/research support from: AbbVie, Chugai, Daiichi-Sankyo, Eisai, Mitsubishi-Tanabe, Takeda, and UCB., Arthur Kavanaugh Consultant of: AbbVie, Amgen, AstraZeneca, Bristol-Myers Squibb, Celgene, Janssen, Pfizer, Roche, and UCB., Grant/research support from: AbbVie, Amgen, AstraZeneca, Bristol-Myers Squibb, Celgene, Janssen, Pfizer, Roche, and UCB., Daniel Aletaha Consultant of: AbbVie, Amgen, Eli Lilly, Gilead, Janssen, Novartis, Pfizer, Roche, Sanofi, and UCB., Grant/research support from: AbbVie, Amgen, Eli Lilly, Gilead, Janssen, Novartis, Pfizer, Roche, Sanofi, and UCB., Peter C. Taylor Speakers bureau: AbbVie, Biogen, Bristol-Myers Squibb, Celgene, Celltrion, Eli Lilly, Galapagos, Gilead, GlaxoSmithKline, Janssen, Fresenius, Nordic Pharma, Pfizer, Roche, Sanofi, and UCB., Consultant of: AbbVie, Biogen, Bristol-Myers Squibb, Celgene, Celltrion, Eli Lilly, Galapagos, Gilead, GlaxoSmithKline, Janssen, Fresenius, Nordic Pharma, Pfizer, Roche, Sanofi, and UCB., Grant/research support from: AbbVie, Biogen, Bristol-Myers Squibb, Celgene, Celltrion, Eli Lilly, Galapagos, Gilead, GlaxoSmithKline, Janssen, Fresenius, Nordic Pharma, Pfizer, Roche, Sanofi, and UCB., In-Ho Song Shareholder of: AbbVie, Employee of: AbbVie, Tim Shaw Shareholder of: AbbVie, Employee of: AbbVie, Yanna Song Shareholder of: AbbVie, Employee of: AbbVie, Ryan DeMasi Shareholder of: AbbVie, Employee of: AbbVie, Mira Ali Shareholder of: AbbVie, Employee of: AbbVie, Roy Fleischmann Consultant of: AbbVie, Amgen, Bristol-Myers Squibb, Eli Lilly, Gilead, GlaxoSmithKline, Janssen, Novartis, Pfizer, Sanofi-Aventis, and UCB., Grant/ research support from: AbbVie, Amgen, Bristol-Myers Squibb, Eli Lilly, Gilead, GlaxoSmithKline, Janssen, Novartis, Pfizer, Sanofi-Aventis, and UCB. DOI: 10.1136/annrheumdis-2021-eular.474

\begin{tabular}{|l|l|}
\hline POS0654 IMPACT OF CONCOMITANT GLUCOCORTICOIDS \\
ON THE CLINICAL EFFICACY AND SAFETY OF \\
UPADACITINIB IN PATIENTS WITH RHEUMATOID \\
ARTHRITIS: AN AD HOC ANALYSIS OF DATA FROM \\
THREE PHASE 3 STUDIES
\end{tabular}

B. Combe ${ }^{1}$, F. Buttgereit ${ }^{2}$, A. Ostor ${ }^{3}$, R. Xavier ${ }^{4}$, A. Saraux ${ }^{5}$, C. Daridon ${ }^{6}$, K. Famulla ${ }^{7}$, Y. Song ${ }^{8}$, I. Lagunes-Galindo ${ }^{8}$, G. R. Burmester ${ }^{2} .{ }^{1}$ Department of Rheumatology, CHU Montpellier, Montpellier University, Montpelier, France; ${ }^{2}$ Charité University Medicine, Rheumatology, Berlin, Germany; ${ }^{3}$ Cabrini Hospital, Monash University \& Emeritus Research Melbourne, Melbourne, Australia; ${ }^{4}$ Hospital de Clínicas de Porto Alegre, Universidade Federal do Rio Grande do Sul, Porto Alegre, Brazil; ${ }^{5}$ Department of Rheumatology, UBO, CHU, INSERM 1227 (LBAI), Brest, France; ${ }^{6}$ AbbVie France, Rheumatology, Rungis, France; ${ }^{7}$ AbbVie Deutschland GmbH \& Co. KG, Rheumatology, Wiesbaden, Germany; ${ }^{8}$ AbbVie Inc., Rheumatology, North Chicago, United States of America

Background: Glucocorticoid (GC) therapy has strong anti-inflammatory effects and helps slow radiographic progression in $\mathrm{RA}^{1}$; however, GCs can be associated with adverse events (AEs) such as infection, especially with long-term use and higher doses.

Objectives: To evaluate the impact of baseline GCs on the efficacy and safety of upadacitinib (UPA) with or without concomitant conventional synthetic DMARDs (csDMARDs).

Methods: In this ad hoc analysis of three Phase 3 studies, patients with inadequate response to MTX (MTX-IR) receiving UPA $15 \mathrm{mg}$ once daily (QD) or placebo (PBO) + csDMARDs in SELECT-NEXT, and MTX-IR/MTX-naïve patients receiving UPA $15 \mathrm{mg}$ QD monotherapy or MTX monotherapy in SELECT-MONOTHERAPY/SELECT-EARLY, respectively, were included. Efficacy outcomes, including measures of remission and low disease activity (LDA) determined by DAS in 28 joints using CRP (DAS28[CRP]; <2.6/ $\leq 3.2$ ) and Clinical Disease Activity Index (CDAI; $\leq 2.8 / \leq 10)$, were assessed and stratified by baseline GC use. Patients were permitted to receive oral GCs $\leq 10 \mathrm{mg} /$ day (prednisone equivalent) at baseline with no adjustment permitted until Week 24/26/48 Safety was reported as number and proportion of patients with AEs. Data were analyzed descriptively with no statistical comparisons between groups or doses.

Results: Of 1,506 patients included in the analysis, $737(48.9 \%)$ were receiving baseline GCs (mean dose $6.2 \mathrm{mg} /$ day). Baseline characteristics were broadly similar across treatment groups; SELECT-EARLY, which enrolled MTX-naïve patients, generally had the shortest duration of RA and higher CRP levels. Across UPA treatment groups, concomitant GCs generally did not influence the proportions of patients achieving remission (Figure 1). In SELECT-NEXT, clinical responses with UPA $15 \mathrm{mg}$ in combination with cSDMARDs were similar irrespective of concomitant GC use (Figure 1). Within SELECT-MONOTHERAPY, responses in patients receiving UPA $15 \mathrm{mg}$ without concomitant csDMARDs or GCs were higher than those in patients receiving MTX alone, but were numerically lower than in those receiving UPA $15 \mathrm{mg}$ with GCs (Figure 1). However, this was not observed within SELECT-EARLY, where clinical responses in patients receiving UPA $15 \mathrm{mg}$ monotherapy without GCs were higher than in those patients receiving UPA $15 \mathrm{mg}$ with GCs for both DAS28(CRP) $<2.6(40.6 \%$ vs $29.9 \%$, respectively) and CDAI $\leq 2.8(20.0 \%$ vs $11.6 \%$, respectively) (Figure 1$)$. A similar trend was observed for LDA. Serious AEs, AEs leading to discontinuation, and AEs of special interest, including infections (such as herpes zoster), were broadly similar in the UPA groups irrespective of concomitant GC use (table of safety data will be presented).

Conclusion: UPA $15 \mathrm{mg}$ in combination with csDMARDs or as monotherapy was effective in achieving remission and LDA, irrespective of concomitant GC use Safety of UPA, including incidence of infection, appeared largely unaffected by concomitant GC use.

\section{REFERENCES:}

[1] Kirwan JR, et al. Cochrane Database Syst Rev 2007;1:CD006356.

\section{Figure. Efficacy in patients receiving UPA or PBO with/without csDMARDs, and with/without GCs}
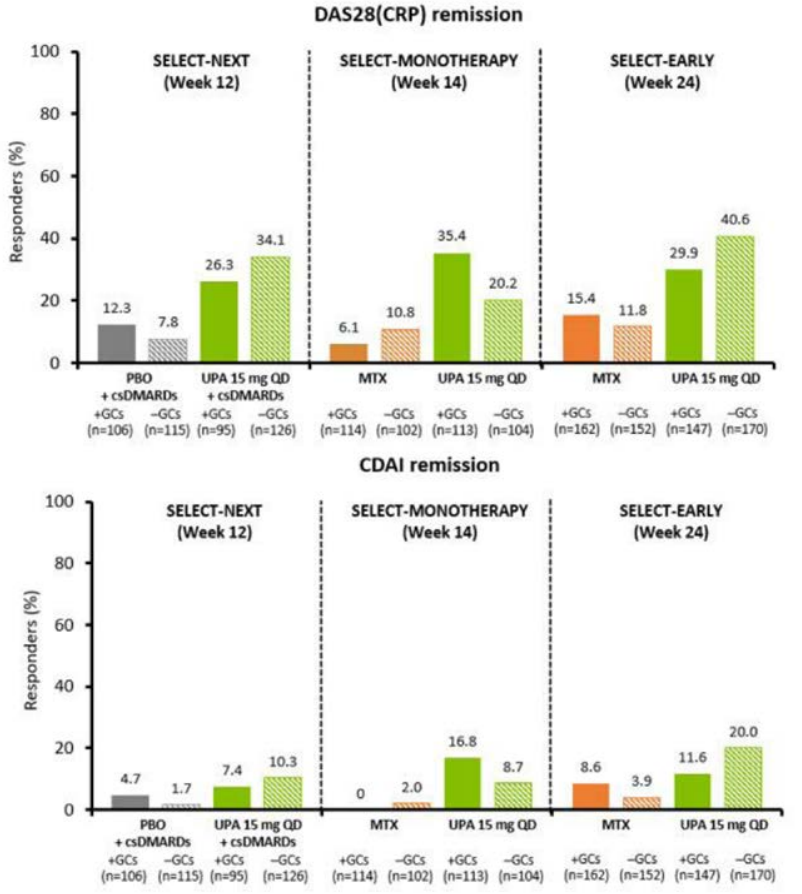

Non-responder imputation.

CDAI, Clinical Disease Activity Index; CSDMARD, conventional synthetic DMARD; DAS28(CRP), Disease Activity Score in 28 joints using CRP; GC, glucocorticoid; PBO, placebo; $Q D$, once daily; UPA, upadacitinib. 